\title{
Comparison of equatorial GPS-TEC observations over an African station and an American station during the minimum and ascending phases of solar cycle 24
}

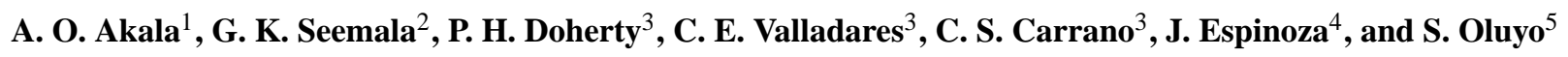 \\ ${ }^{1}$ Department of Physics, University of Lagos, Akoka, Yaba, Lagos, Nigeria \\ ${ }^{2}$ Research Institute for Sustainable Humanosphere, Kyoto University, Kyoto, Japan \\ ${ }^{3}$ Institute for Scientific Research, Boston College, Chestnut Hill, MA, USA \\ ${ }^{4}$ Jicamarca Radio Observatory, Lima, Peru \\ ${ }^{5}$ Department of Physical Science, Yaba College of Technology, Yaba, Lagos, Nigeria \\ Correspondence to: A. O. Akala (akalaovie2004@yahoo.com)
}

Received: 10 April 2013 - Revised: 23 August 2013 - Accepted: 23 October 2013 - Published: 22 November 2013

\begin{abstract}
GPS-TEC data were observed at the same local time at two equatorial stations on both longitudes: Lagos $\left(6.52^{\circ} \mathrm{N}, 3.4^{\circ} \mathrm{E}, 3.04^{\circ} \mathrm{S}\right.$ magnetic latitude), Nigeria; and $\mathrm{Pu}-$ callpa $\left(8.38^{\circ} \mathrm{S}, 74.57^{\circ} \mathrm{W}, 4.25^{\circ} \mathrm{N}\right.$ magnetic latitude), Peru during the minimum $(2009,2010)$ and ascending (2011) phases of solar cycle 24 . These data were grouped into daily, seasonal and solar activity sets. The day-to-day variations in vertical TEC (VTEC) recorded the maximum during 14:0016:00 LT and minimum during 04:00-06:00 LT at both longitudes. Seasonally, during solar minimum, maximum VTEC values were observed during March equinox and minimum during solstices. However, during the ascending phase of the solar activity, the maximum values were recorded during the December solstice and minimum during the June solstice. VTEC also increased with solar activity at both longitudes. On longitude by longitude comparison, the African GPS station generally recorded higher VTEC values than the American GPS station. Furthermore, harmonic analysis technique was used to extract the annual and semi-annual components of the amplitudes of the TEC series at both stations. The semi-annual variations dominated the TEC series over the African equatorial station, while the annual variations dominated those over the American equatorial station. The GPS-TEC-derived averages for non-storm days were compared with the corresponding values derived by the IRI-2007 with the NeQuick topside option. The NeQuick option of IRI-2007 showed better performance at the American sector
\end{abstract}

than the African sector, but generally underestimating TEC during the early morning hours at both longitudes.

Keywords. Ionosphere (Equatorial ionosphere)

\section{Introduction}

The ionosphere over the equatorial latitudes is highly dynamic, and consequently poses serious threats to communication and navigation systems (Akala et al., 2010a, 2011, 2012). The ionospheric parameter that has an over-bearing influence on the GPS based communication and navigation systems is the total electron content (TEC) (Akala et al., 2013). The range errors in GPS signals are directly proportional to TEC; hence, any variations thereof are a matter of concern (Galav et al., 2010). Consequently, detailed knowledge of TEC distributions and variations will be a reliable tool for successful GPS based navigation. To this end, a number of regions have established regional networks of GPS stations, to provide real-time forecasting of ionospheric TEC variations for aviation applications. Unfortunately, such a network has not been built in Africa.

The African continent has the largest landmass under the equatorial anomaly strip, with an ionosphere that is characterised with complex electrodynamic structures that are not yet well understood. Perhaps, this could be largely due to the sparse results of ionospheric studies from the continent. Earlier, Burke et al. (2004); Gentile et al. (2006, 2011), 
using the Defense Metrological Satellite Programme, DMSP; Hei et al. (2005), using the Atmospheric Explorer E, AEE, and Fejer et al. (2008); Kil et al. (2009a, b), using Republic of China satellite, ROCSAT-1 observations, reported the dominance of ionospheric irregularities (plasma bubbles) over the equatorial African ionosphere during all the seasons except the December solstice, in comparison with those of other equatorial longitudes, namely: the Pacific, Indian and American longitudes. For better understanding of the electrodynamics over the African ionosphere, especially in the equatorial region of the continent, it is pertinent to compare the ionospheric behaviour over the region with other regions with better history of ionospheric studies (e.g. South America).

Prior to the end of solar cycle 23, when GPS receivers were installed at some locations across Africa, TEC data were generally lacking in Africa, and characterisation of TEC over the region has majorly relied on empirical models (e.g. the International Reference Ionosphere (IRI)) and in situ satellite (e.g. TOPEX) measurements. At times, results from these models do show discrepancies from real observations. Consequently, analyses of real-time observations of ionospheric parameters are significant indices for improving the overall effectiveness of these models. IRI-2007 provides three different options (NeQuick, IRI01-corr, and IRI-2001) for the topside electron density, and two options for bottomside thickness B0. Of the three options of IRI-2007, NeQuick seems to provide the best predictions of ionospheric TEC (Coisson et al., 2006; Chauhan and Singh, 2010). For this reason, this study compares only the NeQuick option of IRI-2007 with the GPSderived TEC.

We also investigated the annual and semiannual variations of TEC series at both stations. One basic mathematical apparatus that could illustrate annual and semiannual variations of ionospheric data series, for better understanding of ionospheric climatology is the orthogonal eigenfunctions expansion technique (e.g. Fourier analysis) (Zhao et al., 2005, 2007; Liu et al., 2009; A et al., 2012), in which the first harmonic and higher-order harmonics are extracted. The semiannual variation of the ionosphere has been studied to show ionization maxima in equinoxes and minima in solstices (Rishbeth and Setty, 1961); the maxima arise from the optimized effect of the thermospheric composition and solar zenith angle at equinoxes when the thermospheric circulation is most symmetric. Fuller-Rowell (1998) suggested that the increased internal mixing at solstices can explain the semiannual neutral density variation, and it was proposed that the global-scale circulation at solstice acts like a huge spoon to mix the major thermospheric species (oxygen and nitrogen), causing less diffusive separation of the species at solstices. As a consequence, the ratio of $\mathrm{O} / \mathrm{N}_{2}$ has clear annual and semiannual variations at most longitudes. Thermospheric winds push plasma up and down geomagnetic field lines and transport plasma from one hemisphere to the other by modulating the field-aligned flows, which further influences the latitudinal structure of plasma, thereby leading to hemispheric asymmetries (Watanabe et al., 1995).

Pending the time that a trustworthy GPS network will be in vogue in Africa, contributions from individual GPS receivers, most of which were just installed towards the end of the last solar cycle (cycle 23), basically for scientific studies, will continue to play pivotal roles in providing necessary data analysis and interpretation on which the understanding of ionospheric phenomenon over Africa could be based, especially in the equatorial region of the continent.

The goal of this study is to compare ionospheric TEC characteristics over an African GPS station and an American GPS station on diurnal and seasonal scales, and to study the performance of IRI-2007 (NeQuick option) predictions of TEC at both longitudes during the minimum and ascending phases of solar cycle 24 . The motive is to present preliminary results that could spur future investigations on the practicality of using documented histories of TEC or general ionospheric electrodynamics over the equatorial South American region as the benchmark for defining the expected TEC/ionospheric electrodynamics over other equatorial regions of the world with limited archives of ionospheric studies (e.g. Africa). Additionally, the previous deep solar minimum (2009) was the lowest among the past few solar cycles, therefore, 2009 TEC data present the opportunities for sensitivity studies of quiettime ionospheric phenomena. Furthermore, these low solar activity observations may assist in the future modelling of the lowest range error margins for GPS based navigation system in the African and American equatorial sectors.

\section{Data and method of analysis}

GPS-TEC data at the same local time during the minimum (2009 \{ Zurich sunspot number (Rz): 3.0$\}$; 2010 \{ Rz: 16.5 \}) and ascending (2011 \{ Rz: 56.0$\})$ phases of solar cycle 24 at two stations, namely; Lagos $\left(6.52^{\circ} \mathrm{N}, 3.4^{\circ} \mathrm{E}, 3.04^{\circ} \mathrm{S}\right.$ magnetic latitude), Nigeria [AFRICA] and Pucallpa $\left(8.38^{\circ} \mathrm{S}\right.$, $74.57^{\circ} \mathrm{W}, 4.25^{\circ} \mathrm{N}$ magnetic latitude), Peru [SOUTH AMERICA] were used for this investigation.

Several NovAtel GSV4004B GPS receivers, being managed by Boston College were installed towards the end of the last solar cycle (cycle 23) in the instrument arrays of Lowlatitude Ionospheric Sensor Network (LISN). Specifically, the GPS receiver at Pucallpa became operational in March 2007, while that of Lagos became operational in February 2008. LISN is an international project that monitors ionospheric phenomenon, with special interest on the low-latitude ionosphere. The project is being managed by the Geophysical Institute of Peru, in collaboration with other international institutions. The data from all the instruments in the network are usually uploaded to a Central Server, being hosted by the Geophysical Institute of Peru.

LISN TEC data are archived in Receiver INdependent Exchange (RINEX) format. The RINEX formatted files for the 

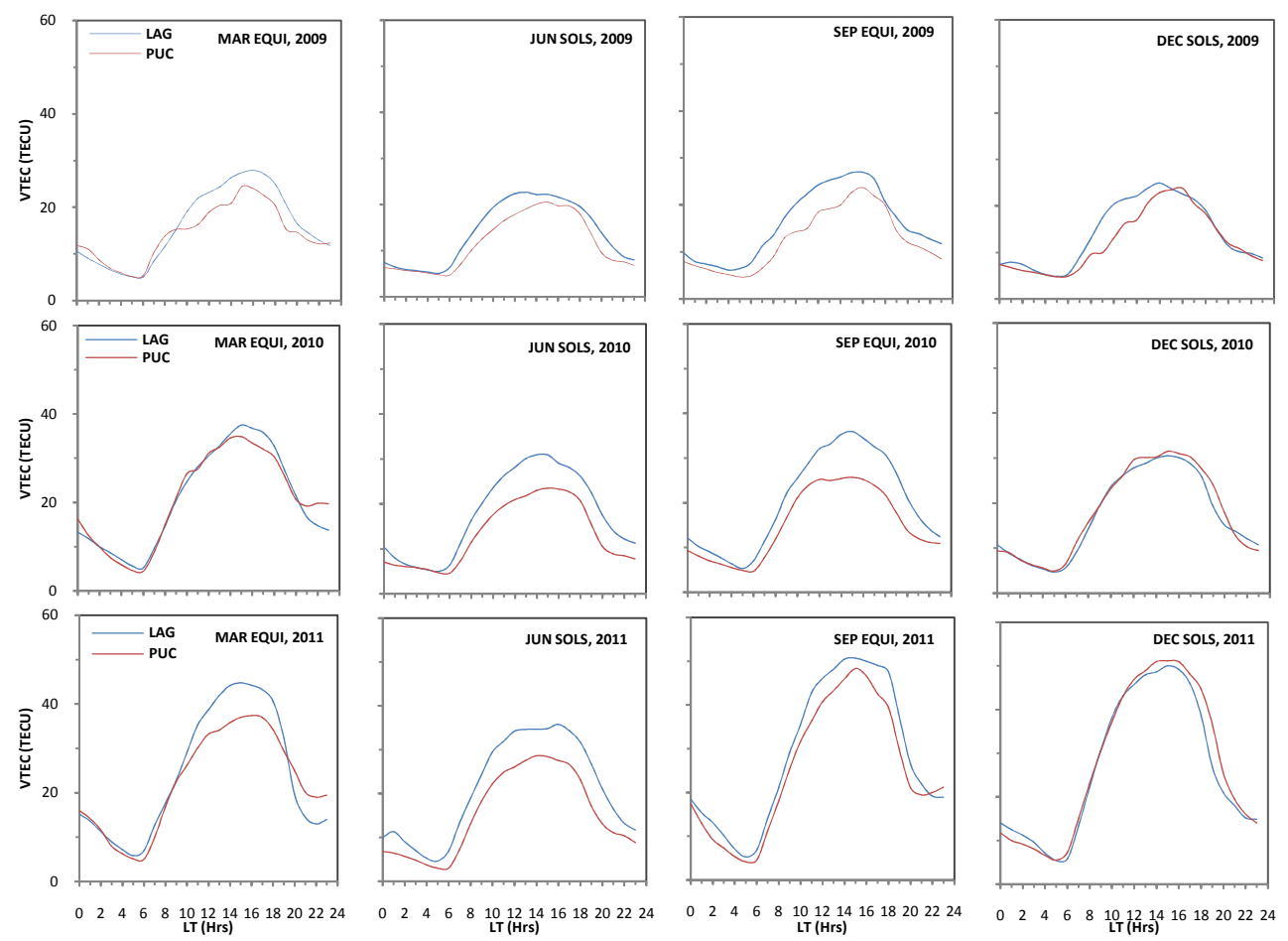

Fig. 1. Diurnal variation of the mean VTEC values for all seasons at Lagos and Pucallpa stations during 2009, 2010, and 2011 respectively.

two stations under investigation for years 2009-2011 were processed by the GPS-TEC RINEX files processing software developed by the second author of this paper. Receiver and satellites biases, obtained from the Data Centre of the Bern University, Switzerland were carefully removed from the raw slant TEC data to produce the corresponding true slant TEC. The GPS-TEC RINEX files processing software converts the true slant TEC to vertical TEC (VTEC) by assuming that the ionosphere is a thin shell at an altitude of $350 \mathrm{~km}$, via a mapping function given by Mannucci et al. (1993); Ma and Maruyama (2003).

Furthermore, in order to eliminate multipath effects from the data, elevation angle cut-off of $30^{\circ}$ was adopted. The processed VTEC data were grouped into daily, seasonal and solar activity (annual) sets. For the seasonal grouping of the data, we used the associated three months of data for each season: March equinox (February, March, and April), June solstice (May, June, and July), September equinox (August, September, and October), and December solstice (November, December, and January) (Akala et al., 2010b). All the measurements within the hourly bin of a given dataset were averaged together to provide a single data point for each local time hour. The differences of the hourly averages of data at Pucallpa from those at Lagos at the same local time (LT) were evaluated to study the extent of data correlations at both longitudes. We also determined the relative variations (RV) of VTEC data at the African and American stations via:
$\mathrm{RV}=\frac{\mathrm{VTEC}_{\mathrm{Af}}-\mathrm{VTEC}_{\mathrm{Am}}}{\left(0.5 \cdot\left(\mathrm{VTEC}_{\mathrm{Af}}+\mathrm{VTEC}_{\mathrm{Am}}\right)\right)}$

Twelve point Fourier analysis was performed on the annual TEC data (monthly averages at a given local time as a representative of each month) from both stations at the same local time so as to derive the annual (A1) and semiannual (A2) components of the amplitude of the TEC series. Thereafter, these components were extracted and analysed. Finally, we compared the hourly averages of the GPS-derived TEC for each season at the two stations for non-storm days with the corresponding values derived by the NeQuick option of IRI2007. A storm day was defined as a day with the Kp index greater than 2 . We specified $2000 \mathrm{~km}$ for upper boundary of electron density profile and B0 Table option for bottomside electron density profile shape parameter.

Furthermore, we determined the percentage deviations (\% Dev) of GPS-derived TEC data from those derived by IRI2007, using Eq. (2).

$\% \operatorname{Dev}=\left(\frac{\mathrm{Obs}-\mathrm{IRI}}{\mathrm{Obs}}\right) \times 100$

where Obs represents the GPS-derived TEC values, and IRI represents those derived by IRI-2007. 

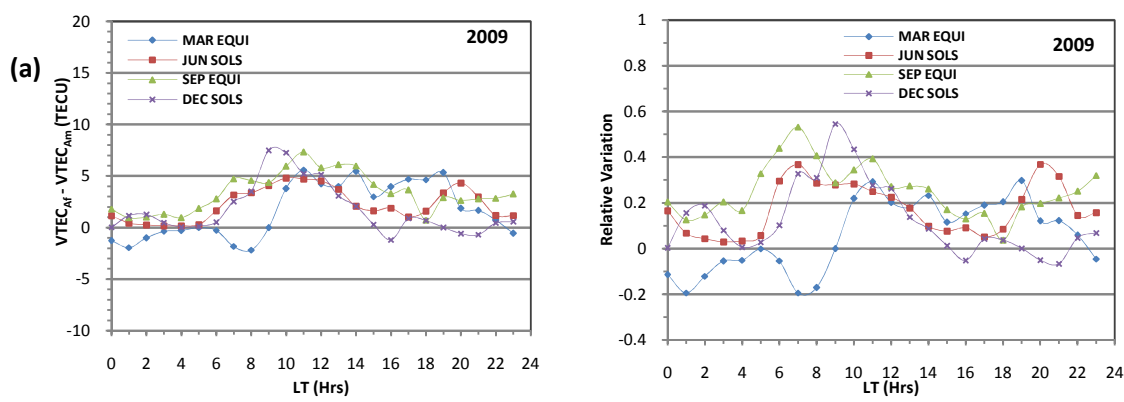

(d)
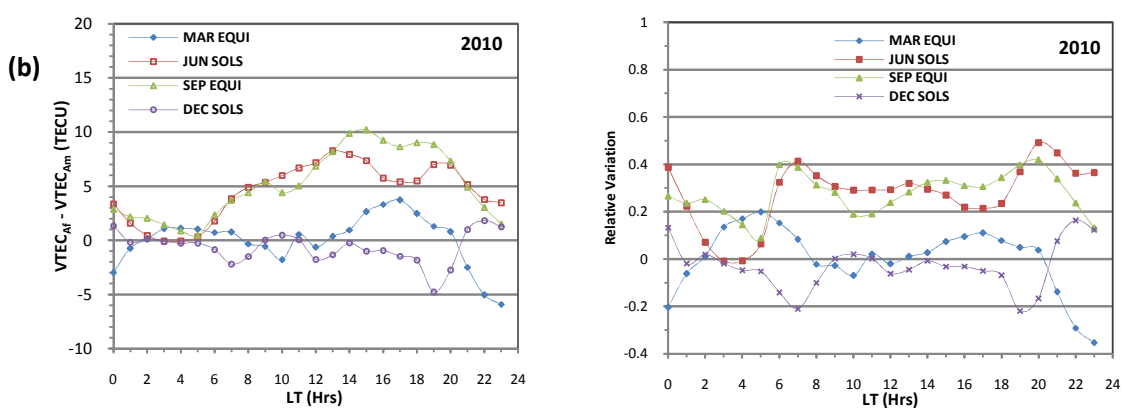

(e)
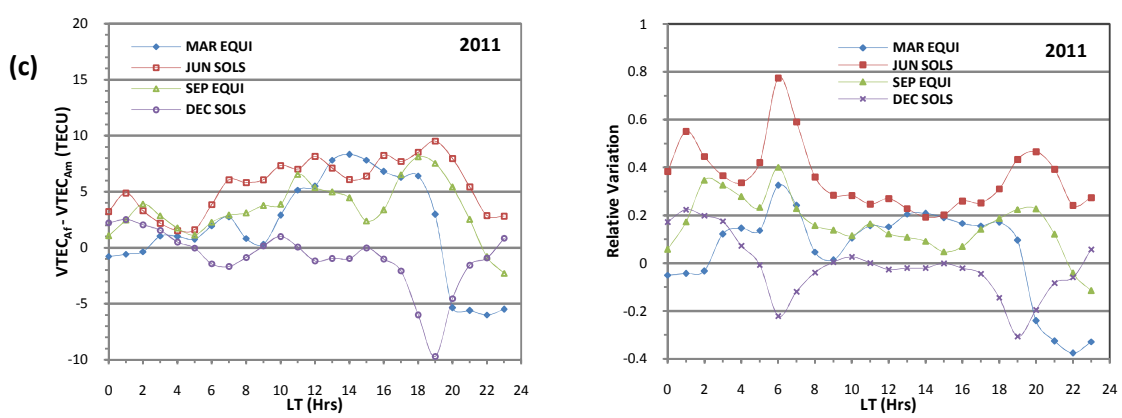

(f)

Fig. 2. Seasonal deviations of the mean VTEC values at Pucallpa from those at Lagos, during (a) 2009 (b) 2010, and (c) 2011. Corresponding relative variations during (d) 2009 (e) 2010, and (f) 2011.

\section{Results}

Figure 1 shows the diurnal variations of the mean VTEC values over Lagos and Pucallpa for all seasons during years 2009; 2010 (solar minimum) and 2011 (ascending phase of solar activity). Diurnally, the mean VTEC values showed early morning (post-sunrise) minimum, and post-midday maximum.

During the solar minimum (2009) at the Lagos station, March equinox (MAR EQUI) recorded the highest VTEC value ( $\sim 28$ TECU) at 16:00 LT. September equinox (SEP EQUI) recorded VTEC peak value of 26.5 TECU at 16:00 LT. The diurnal plots of the mean VTEC for June and December solstices (JUN SOLS and DEC SOLS) almost superimposed, with a maximum value of about $22 \mathrm{TECU}$ at 04:00 LT. A seasonal minimum value of about 5.3 TECU at 04:00 LT was recorded during all the seasons. At Pucallpa, MAR EQUI recorded the highest VTEC value $(\sim 27.4 \mathrm{TECU})$ at 15:00 LT. JUN SOLS recorded VTEC peak value of 21.5 TECU at 15:00 LT. SEP EQUI recorded VTEC peak value of 26.9 TECU at 14:00 LT, while DEC SOLS recorded a maximum value of about 22.9 TECU. A common minimum TEC value of about 4.75 TECU at 05:00 LT was recorded during all the seasons.

In 2010, at the Lagos station, MAR EQUI recorded the highest VTEC value ( 37.5 TECU) at 15:00 LT, while SEP EQUI recorded VTEC peak value of 35.7 TECU at 15:00 LT. The diurnal plots of the mean VTEC for JUN SOLS and DEC SOLS superimposed, with maximum value of about 30.5 TECU at 15:00 LT. A common minimum TEC value of about 4.66 TECU at 05:00 LT was recorded for all the seasons. At the Pucallpa station, MAR EQUI recorded the highest VTEC value ( 34.8 TECU) at 15:00 LT, while DEC SOLS recorded VTEC peak value of 31.5 TECU at 15:00 LT. SEP EQUI recorded VTEC peak value of 25.7 TECU at 15:00 LT and 23.5 TECU at 16:00 LT for the JUN SOLS. A common minimum TEC value of about 4.91 TECU at 05:00 LT was recorded for all the seasons. 

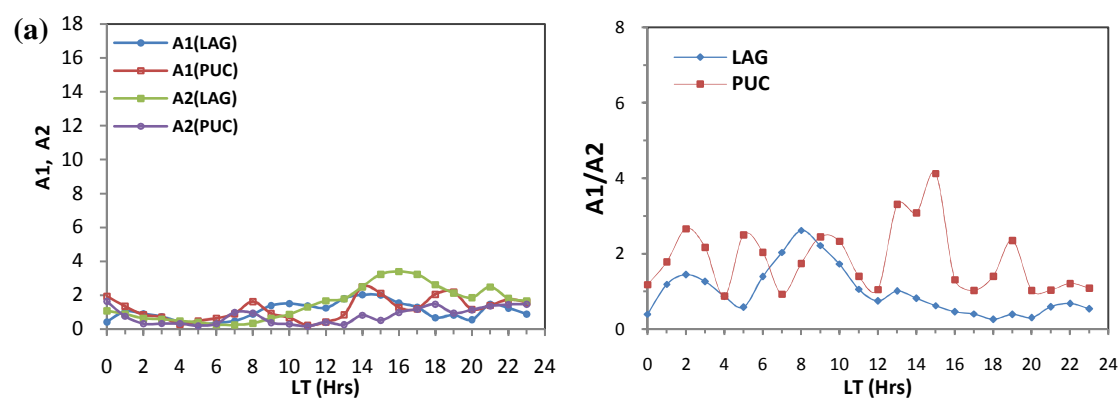

(d)
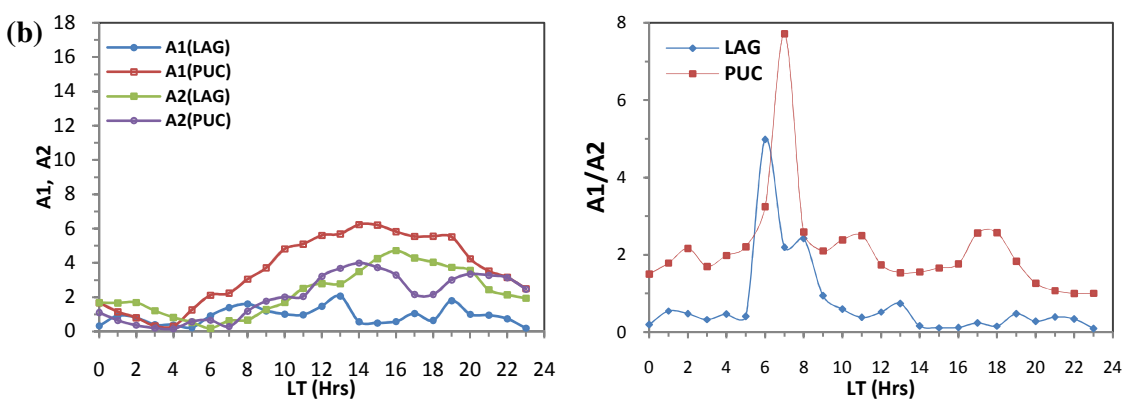

(e)
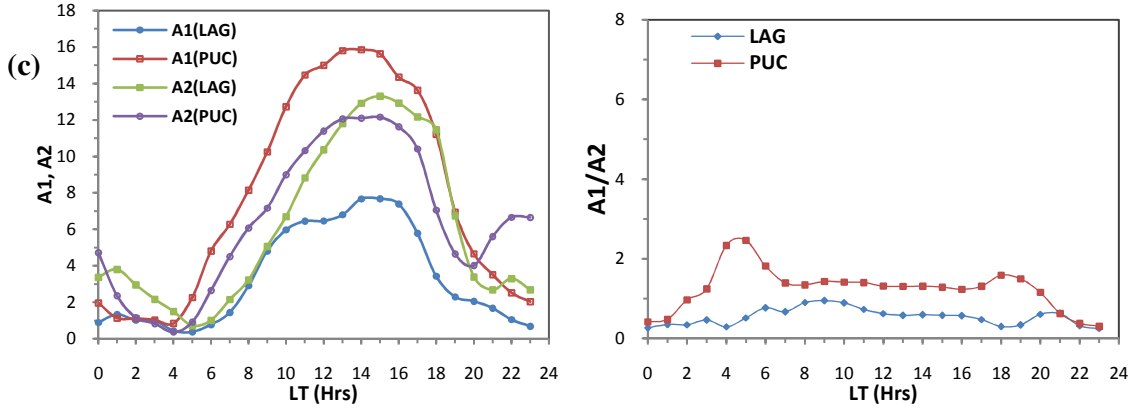

(f)

Fig. 3. Amplitudes of the annual (A1) and semiannual (A2) components over the same local time at Lagos and Pucallpa stations during (a) 2009, (b) 2010 and (c) 2011. Corresponding A1/A2 ratio at both stations during (d) 2009, (e) 2010 and (f) 2011.

In 2011, at the Lagos station, SEP EQUI and DEC SOLS recorded the highest VTEC value ( $~ 51$ TECU), while MAR EQUI recorded VTEC peak value of 45 TECU, all at 15:00 LT, and 36 TECU at 16:00 LT for the JUN SOLS. A common minimum TEC value of 5.5 TECU at 05:00 LT was recorded for all the seasons. At the Pucallpa station, DEC SOLS recorded the highest VTEC value ( $\sim 51$ TECU), SEP EQUI recorded VTEC peak value of 48.3 TECU at 15:00 LT. MAR EQUI recorded VTEC peak value of $37 \mathrm{TECU}$ at 16:00 LT, with a minimum of 5.5 TECU at 05:00 LT for the DEC SOLS and MAR EQUI. JUN SOLS recorded VTEC peak value of 28.5 TECU at 14:00 LT, with a seasonal minimum of 4.2 TECU at 06:00 LT for the JUN SOLS and SEP EQUI. The observed enhancement in TEC records in the last quarter of 2011 could be attributed to the corresponding enhancement in solar flux, signifying a gradual transition to the year of high solar activity (Fig. 4a-b). Seasonally, with the exception of the 2011 VTEC data which showed DEC SOLS and SEP EQUI maximum, and minimum during JUN SOLS, 2009 and 2010 showed maximum VTEC peaks during the
MAR EQUI, and minimum during the JUN SOLS at both stations.

Figure $2 a-c$ show the seasonal deviations of the mean VTEC values at Pucallpa from the mean VTEC values at Lagos, at the same local time (LT) for 2009, 2010 and 2011 respectively. Figure $2 \mathrm{~d}-\mathrm{e}$ show the corresponding relative variations of VTEC at the two stations. The data at the two stations are reasonably correlated during the presunrise hours (00:00-06:00), with marked disparities between 07:00-18:00 for the three years. Overall, the recorded data at the Lagos station were higher than those recorded at Pucallpa. However, the Pucallpa VTEC data leads those of Lagos during the DEC SOLS, and the post-midnight and post-sunset hours in MAR EQUI.

Figure $3 \mathrm{a}-\mathrm{c}$ show the amplitudes of the annual (A1) and semiannual (A2) components of the TEC series over Lagos and Pucallpa the same local time at for 2009, 2010 and 2011 respectively. Figure 3d-e show the corresponding A1/A2 ratio for the two stations. At the Lagos station, the semiannual component is dominant, while the annual component is dominant at the Pucallpa station. Figure 4a 

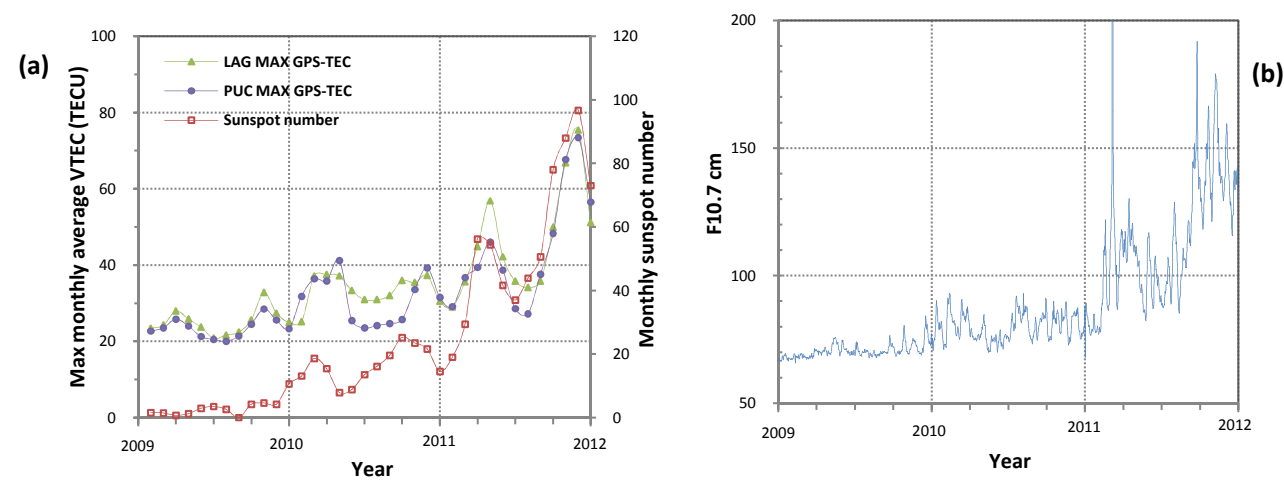

Fig. 4. (a) Plots of monthly sunspot number and the maximum monthly average value of monthly VTEC for 2009, 2010, and 2011 (b) plot of F10.7 cm solar flux for 2009, 2010, and 2011.
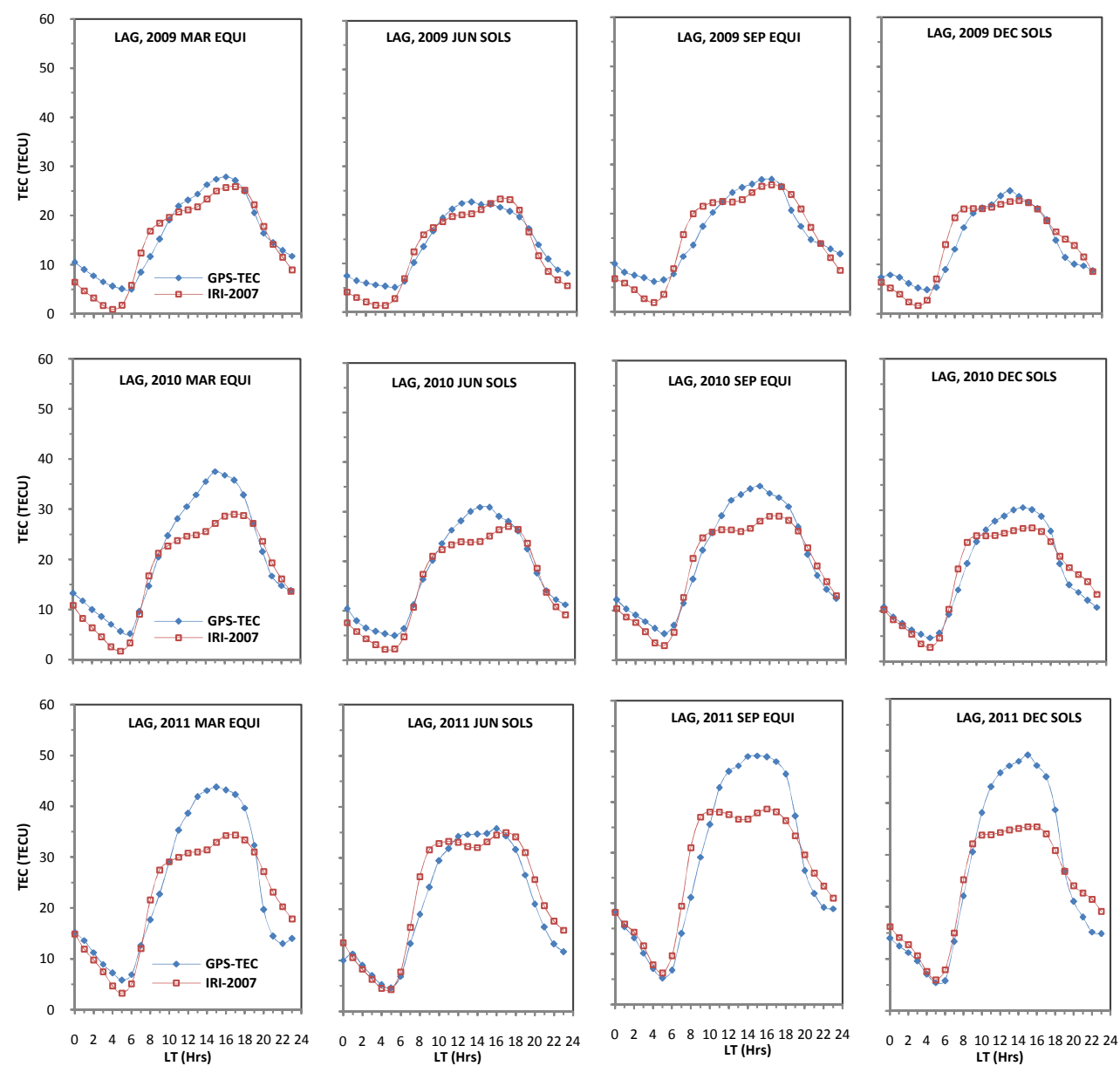

Fig. 5. Comparison of the diurnal variation of the mean GPS-VTEC values (storm days were isolated) with those derived from the IRI-2007 NeQuick topside option for all seasons at Lagos (LAG) during 2009, 2010, and 2011 respectively.

shows the superimposition of the monthly sunspot number on the maximum monthly average value of monthly VTEC for the three years under investigation. VTEC values increase with sunspot number, and the VTEC correlated well with the sunspot number, especially as the solar activity increases.
Figure 4b shows the F10.7 cm solar flux plots for 2009, 2010, and 2011. At both stations, VTEC correlated reasonably well with the F10.7 cm solar flux.

Figure 5 shows the comparison of the diurnal variations of the mean GPS-VTEC values with the storm days removed 

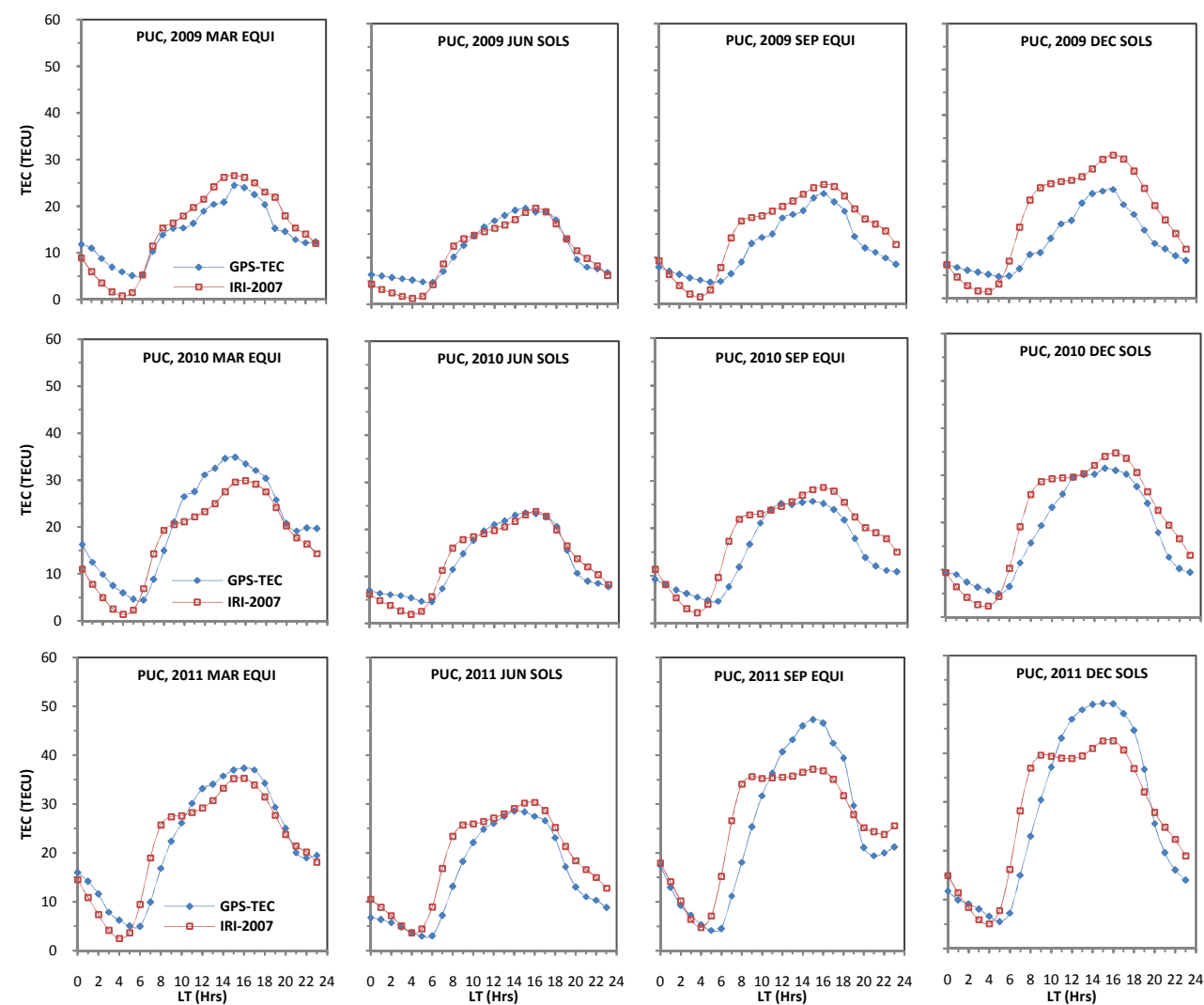

Fig. 6. Comparison of the diurnal variation of the mean GPS-VTEC values (storm days were isolated) with those derived from the IRI-2007 NeQuick topside option for all seasons at Pucallpa (PUC) during 2009, 2010, and 2011 respectively.

before the seasonal averaging for each local time hour, with those derived from the IRI-2007 with the NeQuick topside option for all the seasons at Lagos (LAG) during 2009, 2010, and 2011 respectively. Figure 6 shows a similar comparison for Pucallpa. The years of low solar minimum were characterised with fewer storms, which made the diurnal variations of the GPS-TEC values at both stations for all the seasons when storm days were excluded in the seasonal averaging for each local time hour to be similar to those obtained when storm days were included (Figs. 1, 5 and 6). However, year 2011 was characterised with many storms, particularly in the second half of the year. For the September equinox and December solstice of 2011 with more storm events, the diurnal variations of the seasonal averaging of TEC for each local time hour when storm days were excluded showed lesser values (in the order of 3 TECU) during the day, compared to the diurnal variations of the seasonal averaging of TEC for each local time hour when storm days were included. Table 1 shows the peak and minimum values of the IRI-2007-derived TEC for all the seasons at the Lagos and Pucallpa stations during 2009, 2010, and 2011, while Fig. 7 shows Percentage deviations of the IRI-2007-derived TEC from the GPS observed VTEC values for all the seasons at both stations during 2009, 2010, and 2011 respectively.

\section{Discussion}

The observed post-midday maximum and post-sunrise minimum in the diurnal variations of VTEC (Fig. 1) are consistent with previous theories, such as: (i) the onset and turn-off of solar ionization (Rishbeth et al., 1963; Anderson et al., 2002, 2004; Bilitza et al., 2004). (ii) Zonal component of wind disturbance electric fields is usually westward during the day and eastward at night, with resultant downward and upward equatorial $\mathrm{F}$ region plasma drifts (Woodman and $\mathrm{La}$ Hoz, 1976; Tsunoda, 1985, 2010). (iii) Effects of ambipolar diffusion (Rishbeth et al., 1963; Titheridge, 1995; Akala et al., 2010b).

In Fig. 2a-f, data points below zero of the vertical axes imply that the hourly periods of the seasons where VTEC values were higher at the American longitude, compared to the African longitude, and data points above zero on the vertical axes (which are prevalent) show the opposite. VTEC values are generally higher at Lagos than Pucallpa during the June solstices, September and March equinoxes. Conversely, VTEC values are generally higher at Pucallpa than Lagos during the December solstices. This observed longitudinal variations in VTEC could be attributed to many electrodynamic factors namely: (i) enhancements in ionospheric 

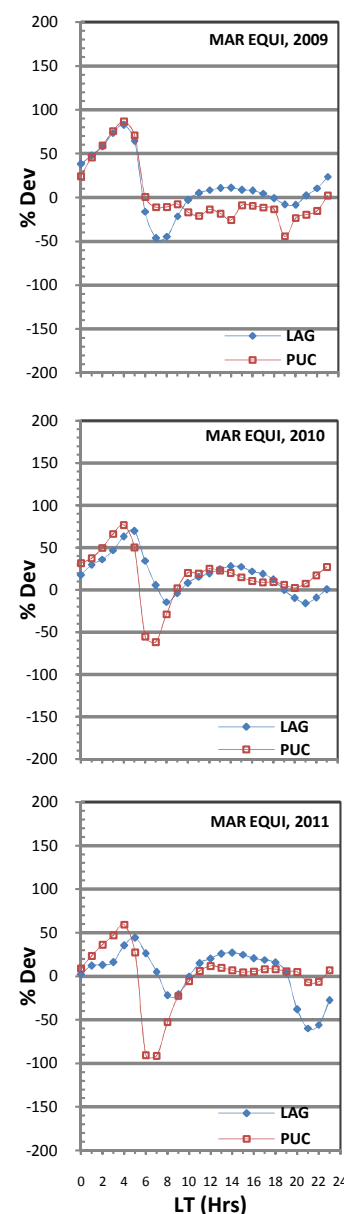
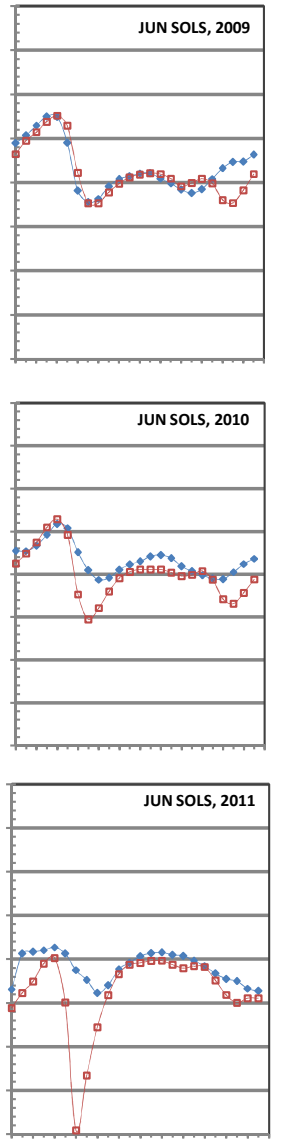

LT (Hrs)
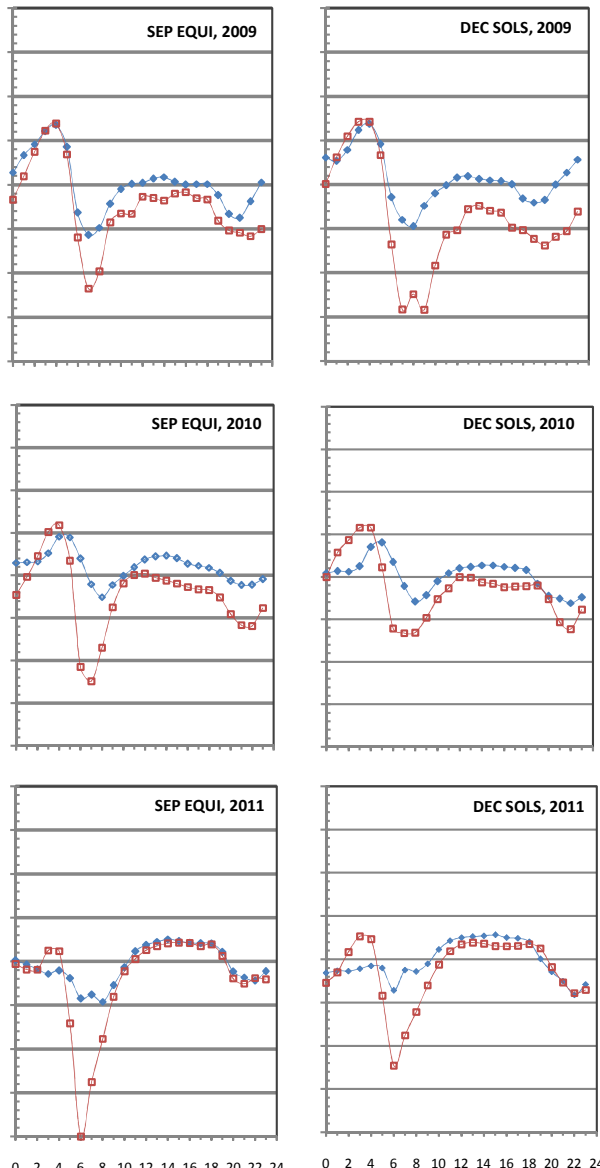

LT (Hrs)

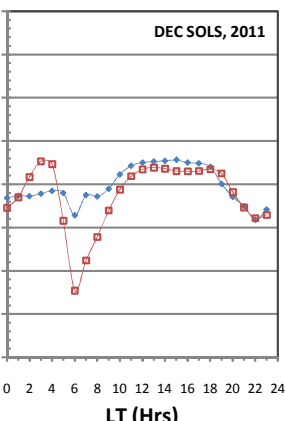

LT (Hrs)

Fig. 7. Percentage variations of the IRI-2007-derived TEC from the GPS observed VTEC values for all seasons at the Lagos and Pucallpa stations during 2009, 2010, and 2011 respectively.

vertical plasma drifts over the African equatorial sector with respect to those over the American equatorial sector during June solstice, and equinoxes (Fejer et al., 2008; Kil et al., 2009a, b, 2012). Klobuchar et al. (1991) showed that the effects of day-time $\boldsymbol{E} \times \boldsymbol{B}$ drifts on TEC were more pronounced at the crests of the equatorial anomaly than at the equator. In earlier longitudinal morphology studies of global vertical drifts variations of ionospheric plasma using ROCSAT-1 data by Fejer et al. (2008) and Kil et al. (2009b), the authors reported the wave number (wave-4) structures in the daytime vertical drifts. These structures recorded longitudinal crests in the neighbourhood of $0^{\circ} \mathrm{E}, 100^{\circ} \mathrm{E}, 200^{\circ} \mathrm{E}$, and $260^{\circ} \mathrm{E}$ during equinoxes, and June solstice, and the amplitudes of these crests were also shown to increase with solar activity. TEC increases with vertical drifts, significantly to the off-equatorial regions via super-fountain effect (Balan et al., 2009). The vertical drifts velocities at the crest are higher $\left(35 \mathrm{~m} \mathrm{~s}^{-1}\right)$ than those at the trough $\left(25 \mathrm{~m} \mathrm{~s}^{-1}\right)$ during the aforementioned seasons. As shown by our results (Fig. 1), Lagos (geographic long: $3.4^{\circ} \mathrm{E}$ ), with more vertical drifts dynamics recorded higher VTEC values than Pucallpa (geographic long: $285.4^{\circ} \mathrm{E}$ ). (ii) Modulations of the zonal electric field by the eastward propagating diurnal tide. (iii) Field aligned currents, resulting from the E region Pederson conductivity, produced at the solar terminator (Tsunoda, 1985, 2010). (iv) Field-aligned flows due to neutral winds could also support longitudinal variations of the topside plasma densities (Balan et al., 1997, 2000). (v) Changes in thermospheric circulations (Fuller-Rowell, 1998).

During the December solstices, higher VTEC values were generally recorded at the American equatorial station (Southern Hemisphere) than the African equatorial station (Northern Hemisphere) (Figs. 1-2). Thermospheric circulation transports neutral gases from the summer hemisphere to the winter hemisphere; thereby making the asymmetry of the energy input with respect to the equator, resulting to transportation of more energy to the equatorial regions from the Southern Hemisphere during the December solstice than from the Northern Hemisphere during the June solstice (Rishbeth et al., 2000). Large-scale inter-hemispheric circulation results into seasonal changes in the $\mathrm{O} / \mathrm{N}_{2}$ ratio. Hence the increase of ion production rate in winter hemisphere might overwhelm 
Table 1. Peak and minimum values of IRI-2007-derived TEC for all the seasons at Lagos and Pucallpa during 2009, 2010 , and 2011.

\begin{tabular}{|c|c|c|c|c|c|c|c|c|c|c|c|c|c|c|c|c|}
\hline \multirow[b]{3}{*}{ Year } & \multicolumn{8}{|c|}{ LAGOS } & \multicolumn{8}{|c|}{ PUCALLPA } \\
\hline & \multicolumn{2}{|c|}{ MAR EQUI } & \multicolumn{2}{|c|}{ JUN SOL } & \multicolumn{2}{|c|}{ SEP EQUI } & \multicolumn{2}{|c|}{ DEC SOLS } & \multicolumn{2}{|c|}{ MAR EQUI } & \multicolumn{2}{|c|}{ JUN SOL } & \multicolumn{2}{|c|}{ SEP EQUI } & \multicolumn{2}{|c|}{ DEC SOLS } \\
\hline & $\begin{array}{r}\text { Max } \\
\text { VTEC } \\
(T E C U)\end{array}$ & $\begin{array}{r}\text { Min } \\
\mathrm{VTEC} \\
(\mathrm{TECU})\end{array}$ & $\begin{array}{r}\text { Max } \\
\text { VTEC } \\
(\mathrm{TECU})\end{array}$ & $\begin{array}{r}\text { Min } \\
\text { VTEC } \\
(T E C U)\end{array}$ & $\begin{array}{r}\text { Max } \\
\text { VTEC } \\
(T E C U)\end{array}$ & $\begin{array}{r}\text { Min } \\
\text { VTEC } \\
(\mathrm{TECU})\end{array}$ & $\begin{array}{r}\text { Max } \\
\text { VTEC } \\
(T E C U)\end{array}$ & $\begin{array}{r}\text { Min } \\
\text { VTEC } \\
(T E C U)\end{array}$ & $\begin{array}{r}\text { Max } \\
\mathrm{VTEC} \\
(\mathrm{TECU})\end{array}$ & $\begin{array}{r}\text { Min } \\
\text { VTEC } \\
(\mathrm{TECU})\end{array}$ & $\begin{array}{r}\text { Max } \\
\text { VTEC } \\
(\mathrm{TECU})\end{array}$ & $\begin{array}{r}\text { Min } \\
\text { VTEC } \\
(T E C U)\end{array}$ & $\begin{array}{r}\text { Max } \\
\text { VTEC } \\
(T E C U)\end{array}$ & $\begin{array}{r}\text { Min } \\
\text { VTEC } \\
(\mathrm{TECU})\end{array}$ & $\begin{array}{r}\text { Max } \\
\text { VTEC } \\
(\mathrm{TECU})\end{array}$ & $\begin{array}{r}\text { Min } \\
\text { VTEC } \\
(T E C U)\end{array}$ \\
\hline 2009 & 25.9 & 1.0 & 22.2 & 1.4 & 23.9 & 1.7 & 25.9 & 1.9 & 26.6 & 0.8 & 20.4 & 1.2 & 25.5 & 1.6 & 31.3 & 1.5 \\
\hline 2010 & 29.0 & 1.7 & 27.1 & 2.2 & 28.9 & 2.9 & 26.5 & 2.8 & 29.6 & 1.4 & 23.8 & 1.9 & 28.6 & 2.3 & 34.4 & 2.4 \\
\hline 2011 & 34.5 & 3.2 & 34.4 & 4.3 & 38.4 & 6.2 & 35.4 & 5.9 & 35.3 & 2.6 & 30.3 & 3.7 & 37.2 & 4.8 & 42.4 & 5.1 \\
\hline
\end{tabular}

the increase in wintertime loss rate. The longitudinal variations of the December and June solstice pre-reversal velocity enhancements are generally anti-correlated, which suggests that they are being controlled by the magnetic field line integrated conductivities.

Another explanation worthy of note was given by Torr and Torr (1973), which suggested that the Southern Hemisphere during the December solstice might have received more energy than the Northern Hemisphere because the offset between the geographic and magnetic poles is larger in the Southern Hemisphere. Our results; general higher VTEC values at the American station over the African station during December solstice (Figs. 1-2) agree with those of Kil et al. $(2009 \mathrm{a}, \mathrm{b})$, which reported a post-sunset crest in ionospheric vertical drifts around the American longitude during December solstice. In addition, our results; general higher VTEC values at the African station over the American station are in agreement with those of Burke et al. (2004); Gentile et al. $(2006,2011)$, which concluded that ionospheric plasma bubbles are more dominant in the African longitude than the American longitude during June solstice and equinoxes, and that during the December solstice, this trend reverses. By implication pre-reversal enhancements (PREs) are comparatively higher around the American longitude than African longitude during December solstice, while during June solstice and equinoxes, this trend reverses. The largest evening velocity peaks occur in the region of largest field-aligned integrated conductivities and magnetic east zonal winds.

Seasonally, variations of VTEC are generally higher at equinox and minimum during June solstice at both stations. These results are consistent with previous studies, and the physical processes involved could be explained by: (i) the usual enhancements in zonal plasma drifts variations in the $\mathrm{F}$ region during March equinox, and diminishing variations during June solstice (Fejer, 1991, 2011; Valladares et al., 1996). (ii) Alignment of the solar terminator with the geomagnetic flux tube (Tsunoda, 1985). (iv) Changes in solar zenith angle, thermospheric composition, and global circulations (Rishbeth and Setty, 1961; Millward et al., 1996). The seasonal composition changes are induced by the prevailing summer-to-winter general circulations (Duncan, 1969). The driving forces of this general circulation are heating due to solar radiation and energy from the solar winds (Millward et al., 1996).
The current study only suspected many electrodynamic processes that might have been responsible for the observed longitudinal differences in VTEC at both longitudes. However, to put these mechanisms on a definitive footing, comparison of electrodynamic parameters, such as the magnitudes and directions of $\boldsymbol{E} \times \boldsymbol{B}$ drifts at both longitudes is required. Incoherent Scatter Radar (ISR) can measure these parameters. ISR has a long history of existence in South America (Jicamarca, Peru), but only at the verge of being installed in Africa (Addis Ababa, Ethiopia). Furthermore, magnetometers data can also be used to derive these parameters. Anderson et al. $(2002,2004)$ gave detailed explanations of how the strength and direction of $\boldsymbol{E} \times \boldsymbol{B}$ drifts could be derived from the data acquired from a pair of magnetometers, one within the equatorial electrojet (EEJ) strip, and the other in the off EEJ region. Intermagnet magnetometers have long existed in Africa and South America. Today, other magnetometer arrays have been included, e.g. MAGnetic Data Acquisition System (MAGDAS) and the African Meridian BField Education and Research (AMBER) [Africa]; and the South American Meridional B-Field Array (SAMBA) [South America].

The harmonic analysis of the data set shown in Fig. 3a$\mathrm{f}$ indicated that the annual component is dominant over $\mathrm{Pu}$ callpa, while the semiannual component is dominant over Lagos. The average A1/A2 ratio for Pucallpa was higher than that of Lagos for the three years investigated. This further shows that A1 (annual component) dominated over Pucallpa, while A2 (semiannual) component dominated over Lagos. These results agree with those of Liu et al. (2009), which reported that the annual component of the $N m \mathrm{~F} 2$ data is comparatively more prominent in the Southern Hemisphere than the Northern Hemisphere.

At both stations, the diurnal variations of the IRI-2007 with the NeQuick topside option derived TEC show the same trend with those derived by GPS measurements (Figs. 5-6). However, the diurnal variations of the IRI-2007 (NeQuick option) TEC show double peaks, first around 09:00 LT, and the second around 17:00 LT, while the corresponding GPSTEC values show single peaks. Furthermore, the minimum values of IRI-2007 (NeQuick option) TEC underestimate the corresponding GPS-TEC values, and they also occurred an hour before the GPS-TEC diurnal minimum. At Lagos, during 2009, the IRI-2007-derived TEC and GPS-TEC matched reasonably well for all seasons, except for the discrepancies 
observed during the early morning hours. As the solar activity increased (2010-2011), the early morning discrepancies collapsed to form reasonable match of the IRI-2007-derived TEC and GPS-TEC, while obvious mis-matches were observed during the day, with the IRI-2007 predictions underestimating TEC values, except for the December solstice of 2011, when the with IRI-2007 with the NeQuick topside option predictions overestimating TEC values.

At Pucallpa, during 2009, the IRI-2007-derived TEC and GPS-TEC matched reasonably well for March and September equinoxes, and June solstice. IRI-2007 with the NeQuick topside option overestimated TEC values during the December solstice. Discrepancies were generally observed during the early morning hours. In 2010, with the exception of March equinox where the IRI-2007 predictions underestimated TEC values during the early morning hours and midday, the matches of the IRI-2007 and GPS-derived TEC data for all other seasons were reasonable, except for the observed post-sunrise discrepancies. For 2011, during the daytime, IRI-2007 predictions underestimated TEC values during September equinox and December solstice. Generally, discrepancies were observed in the morning hours. The early morning variations between the IRI-2007 model values of TEC and the GPS observed values could be attributed to the fact that the shape of the electron density profile is not well predicted by the IRI model option (Ezquer et al., 1995).

As shown in Fig. 7, IRI-2007 (NeQuick) model consistently underestimated TEC between 00:00-06:00 LT for all seasons during the solar minimum years at both stations. The percentage deviations generally showed marked variations between the hours of 01:00-09:00 LT and 21:00-23:00 LT for all the seasons during 2009, 2010 and 2011, with positive deviations around 01:00-05:00 LT, and negative deviations around 06:00-09:00 LT. The negative deviations around 06:00-07:00 LT were most pronounced for all the seasons at the Pucallpa station (up to $200 \%$ for some seasons). The percentage deviations never exceeded 50\% during 10:0019:00 LT. Overall, the NeQuick option of IRI-2007 showed better performance at the American equatorial station than the African equatorial station, especially, as solar activity increases. This could be attributed to long-time availability of data from the American longitude, which has in turn supported update and improvement of IRI-models over the past years.

\section{Conclusions}

We compared GPS-TEC at an African station and an American station during the minimum and ascending phases of solar cycle 24. GPS-TEC data at the same local time at two equatorial stations on both longitudes: Lagos $\left(6.52^{\circ} \mathrm{N}\right.$, $3.4^{\circ} \mathrm{E}, 3.04^{\circ} \mathrm{S}$ magnetic latitude), Nigeria; and Pucallpa $\left(8.38^{\circ} \mathrm{S}, 74.57^{\circ} \mathrm{W}, 4.25^{\circ} \mathrm{N}\right.$ magnetic latitude), Peru were used for the investigation. The main conclusions of the study are:
1. Maximum daily VTEC values were recorded during 14:00-16:00 LT and minimum during 04:00-06:00 LT at both stations. VTEC values also increase with solar activity at both stations.

2. Seasonally, during the solar minimum, maximum VTEC values were observed during the March equinox and minimum during the June solstice at both stations. During the ascending phase of the solar activity, the maximum values were recorded during December solstice at Pucallpa and during September equinox and December solstice at Lagos, while minimum VTEC were recorded during the June solstice at both stations.

3. The correlation between data at the two longitudes was reasonably good during the pre-sunset (00:00-06:00) hours of the day, and not too correlated during the rest of the day, significantly between 07:00-18:00 of the day (Fig. 2).

- At Lagos, semiannual variations dominate over annual variations, while at Pucallpa, the annual variations dominate over semiannual variations (Fig. 3).

4. Generally, on longitude by longitude comparison, the African sector recorded higher VTEC values than the American sector, except during December solstices.

5. IRI-2007 (NeQuick) model showed better performance at the American longitude than the African longitude, especially, as solar activity increases. IRI-2007 with the NeQuick topside option underestimated TEC values at both longitudes during early morning hours. The model results also showed that TEC values were higher at the American longitude than the African longitude, whereas, the GPS-TEC measurements showed otherwise, although the December Solstices model results showed higher values at Pucallpa than Lagos, which were reasonably consistent with observations (Figs. 5-6).

Acknowledgements. The authors thank the Geophysical Institute of Peru/Jicamarca Radio Observatory for providing the GPS-TEC data. The solar flux data were obtained from the NOAA website (ftp://ftp.ngdc.noaa.gov/STP/space-weather/ solar-data/solar-features/solar-radio/noontime-flux/). The authors thank the reviewers for their useful comments and suggestions.

Topical Editor K. Hosokawa thanks two anonymous referees for their help in evaluating this paper. 


\section{References}

A, E., Zhang, D., Ridley, A. J., Xiao, Z., and Hao, Y.: A global model: Empirical orthogonal function analysis of total electron content 1999-2009 data, J. Geophys. Res., 117, A03328, doi:10.1029/2011JA017238, 2012.

Akala, A. O., Oyeyemi, E. O., Somoye, E. O., Adeloye, A. B., and Adewale, A. O.: Variability of $f o \mathrm{~F} 2$ in the African equatorial ionosphere, Adv. Space Res., 45, 1311-1314, 2010a.

Akala, A. O., Adeloye, A. B., and Somoye, E. O.: Ionospheric foF2 variability over the Southeast Asian sector, J. Geophys. Res., 115, A09329, doi:10.1029/2010JA015250, 2010b.

Akala, A. O., Doherty, P. H., Valladares, C. E., Carrano, C., and Sheehan, R.: Statistics of GPS scintillations over South America at three levels of solar activity, Radio Sci., 46, RS5018, doi:10.1029/2011RS004678, 2011.

Akala, A. O., Doherty, P. H., Carrano, C. S., Valladares, C. E., and Groves, K. M.: Impacts of ionospheric scintillations on GPS receivers intended for equatorial aviation applications, Radio Sci., 47, RS4007, doi:10.1029/2012RS004995, 2012.

Akala, A. O., Rabiu, A. B., Somoye, E. O., Oyeyemi, E. O., and Adeloye, A. B.: The Response of African equatorial GPS-TEC to intense geomagnetic storms during the ascending phase of solar cycle 24, J. Atmos. Sol.-Terr. Phys., 98, 50-62, 2013.

Anderson, D., Anghel, A., Yumoto, K., Ishitsuka, M., and Kudeki, E.: Estimating daytime vertical $\boldsymbol{E} \times \boldsymbol{B}$ drift velocities in the equatorial F-region using ground-based magnetometer observations, Geophys. Res. Lett., 29, 1596, doi:10.1029/2001GL014562, 2002.

Anderson, D., Anghel, A., Chau, J., and Veliz, O.: Daytime vertical $\boldsymbol{E} \times \boldsymbol{B}$ drift velocities inferred from ground-based magnetometer observations at low latitudes, Space Weather, 2, S11001, doi:10.1029/2004SW000095, 2004.

Balan, N., Otsuka, Y., and Fukao, S.: New aspects in the annual variation of the ionosphere observed by the MU radar, Geophys. Res. Lett., 24, 2287-2290, doi:10.1029/97GL02184, 1997.

Balan, N., Otsuka, Y., Fukao, S., Abdu, M. A., and Bailey, G. J.: Annual variations of the ionosphere: A review based on MU radar observations, Adv. Space Res., 25, 153-162, doi:10.1016/S02731177(99)00913-8, 2000.

Balan, N., Shiokawa, K., Otsuka, Y., Watanabe, S., and Bailey, G. J.: Super plasma fountain and equatorial ionization anomaly during penetration electric field, J. Geophys. Res., 114, A03310, doi:10.1029/2008JA013768, 2009.

Bilitza, D., Obrou, O. K., Adeniyi, J. O., and Oladipo, O.: Variability of $f o \mathrm{~F} 2$ in the equatorial ionosphere, Adv. Space Res., 34, 1901-1906, 2004.

Burke, W. J., Gentile, L. C., Huang, C. Y., Valladares, C. E., and $\mathrm{Su}, \mathrm{S}$. Y.: Longitudinal variability of equatorial plasma bubbles observed by DMSP and ROCSAT-1, J. Geophys. Res., 109, A12301, doi:10.1029/2004JA010583, 2004.

Chauhan, V. and Singh, O. P.: A morphological study of GPS-TEC data at Agra and their comparison with the IRI model, Adv. Space Res. 46, 280-290, 2010.

Coisson, P., Radicella, S. M., Leitinger, R., and Nava, B.: Topside electron density in IRI and NeQuick: Features and limitations, Adv. Space Res., 37, 937-942, 2006.

Duncan, R. A.: F-region seasonal and magnetic storm behaviour, J. Atmos. Terr. Phys., 31, 59-70, doi:10.1016/00219169(69)90081-6, 1969.
Ezquer, R. G., Ortiz de Adler, N., Radicella, S. M., Mosert de Gonzalez, M., and Manzano, J. R.: IRI and BPM total electron content predictions for Tucuman, Adv. Space Res., 15, 121-124, 1995.

Fejer, B. G.: Low latitude electrodynamics plasma drifts: A review, J. Atmos. Terr. Phys., 53, 677-693, doi:10.1016/00219169(91)90121-M, 1991.

Fejer, B. G.: Low Latitude Ionospheric Electrodynamics, Space Sci. Rev., 158, 145-166, doi:10.1007/s11214-010-9690-7, 2011.

Fejer, B. G., Jensen, J. W., and Su, S.-Y.: Quiet time equatorial $\mathrm{F}$ region vertical plasma drift model derived from ROCSAT-1 observations, J. Geophys. Res., 113, A05304, doi:10.1029/2007JA012801, 2008.

Fuller-Rowell, T. J.: The "thermospheric spoon": A mechanism for the semiannual density variation, J. Geophys. Res., 103, 39513956, doi:10.1029/97JA03335, 1998.

Galav, P., Dashora, N., Sharma, S., and Pandey, R.: Characterisation of low latitude GPS-TEC during very low solar activity phase, J. Atmos. Sol.-Terr. Phy., 72, 1309-1317, 2010.

Gentile, L. C., Burke, W. J., and Rich, F. J.: A climatology of equatorial plasma bubbles from DMSP 1989-2004, Radio Sci., 41, RS5S21, doi:10.1029/2005RS003340, 2006.

Gentile, L. C., Burke, W. J., Roddy, P. A., Retterer, J. M., and Tsunoda, R. T.: Climatology of plasma density depletions observed by DMSP in the dawn sector, J. Geophys. Res., 116, A03321, doi:10.1029/2010JA016176, 2011.

Hei, M. A., Heelis, R. A., and McClure, J. P.: Seasonal and longitudinal variation of large-scale topside equatorial plasma depletions, J. Geophys. Res., 110, A12315, doi:10.1029/2005JA011153, 2005.

Kil, H., Paxton, L. J., and Oh, S.-J.: Global bubble distribution seen from ROCSAT-1 and its association with the evening pre-reversal enhancement, J. Geophys. Res., 114, A06307, doi:10.1029/2008JA013672, 2009a.

Kil, H., Oh, S.-J., Paxton, L. J., and Fang, T. W.: High-resolution vertical E X B drift model derived from ROCSAT-1 data, J. Geophys. Res., 114, A10314, doi:10.1029/2009JA014324, 2009 b.

Kil, H., Lee, W. K., Kwak, Y.-S., Oh, S.-J., Paxton, L. J., and Zhang, Y.: Persistent longitudinal features in the low-latitude ionosphere, J. Geophys. Res., 117, A06315, doi:10.1029/2012JA017570, 2012.

Klobuchar, J. A., Anderson, D. N., and Doherty, P. H.: Model studies of the latitudinal extent of the equatorial anomaly during equinoctial conditions, Radio Sci., 26, 1025-1047, 1991.

Liu, L., Zhao, B., Wan, W., Ning, B., Zhang, M. L., and He, M.: Seasonal variation of the ionospheric electron densities retrieved from Constellation Observing System for Meteorology, Ionosphere, and Climate mission radio occultation measurements, J. Geophys. Res., 114, A02032, doi:10.1029/2008JA013819, 2009.

Ma, G. and Maruyama, T.: Derivation of TEC and estimation of instrumental biases from GEONET in Japan, Ann. Geophys., 21, 2083-2093, doi:10.5194/angeo-21-2083-2003, 2003.

Mannucci, A. J., Wilson, B. D., and Edwards, C. D.: A new method for monitoring the earth's ionosphere total electron content using the GPS global network, Proceedings of ION GPS-93, Institute of Navigation, 1323-1332, 1993.

Millward, G. H., Moffett, R. J., Quegan, S., and Fuller-Rowell, T. J.: Ionospheric F2 layer seasonal and semiannual variations, J. Geophys. Res., 101, 5149-5156, doi:10.1029/95JA03343, 1996. 
Rishbeth, H. and Setty, C. S. G. K.: The F-layer at sunrise, J. Atmos. Terr. Phys., 21, 263-276, doi:10.1016/0021-9169(61)90205-7, 1961.

Rishbeth, H., Lyon, A. J., and Peart, M.: Diffusion in the equatorial F layer, J. Geophys. Res., 68, 2559-2569, doi:10.1029/JZ068i009p02559, 1963.

Rishbeth, H., Müller-Wodarg, I. C. F., Zou, L., Fuller-Rowell, T. J., Millward, G. H., Moffett, R. J., Idenden, D. W., and Aylward, A. D.: Annual and semiannual variations in the ionospheric F2-layer: II. Physical discussion, Ann. Geophys., 18, 945-956, doi:10.1007/s00585-000-0945-6, 2000.

Titheridge, J. E.: Winds in the ionosphere - A review, J. Atmos. Terr. Phys., 57, 1681-1714, 1995.

Torr, M. R. and Torr, D. G.: The seasonal behaviour of the F2layer of the ionosphere, J. Atmos. Terr. Phys., 35, 2237-2251, doi:10.1016/0021-9169(73)90140-2, 1973.

Tsunoda, R. T.: Control of the seasonal and longitudinal occurrence of equatorial scintillations by the longitudinal gradient in integrated E-region Pederson conductivity, J. Geophys. Res., 90, 447-456, doi:10.1029/JA090IA01p00447, 1985.

Tsunoda, R. T.: On equatorial spread F: Establishing a seeding hypothesis, J. Geophys. Res., 115, A12303, doi:10.1029/2010JA015564, 2010.
Valladares, C., Sheehan, R., Basu, S., Kuenzler, H., and Espinoza, J.: The multi-instrumented studies of equatorial thermosphere aeronomy scintillation system: Climatology of zonal drifts, J. Geophys. Res., 101, 26839-26850, doi:10.1029/96JA00183, 1996.

Watanabe, S., Oyama, K.-I., and Abdu, M. A.: Computer simulation of electron and ion densities and temperatures in the equatorial F region and comparison with Hinotori results, J. Geophys. Res., 100, 14581-14590, doi:10.1029/95JA01356, 1995.

Woodman, R. F. and La Hoz, C.: Radar observations of Fregion equatorial irregularities, J. Geophys. Res., 81, 5447-5466, doi:10.1029/JA081i031p05447, 1976.

Zhao, B., Wan, W., Liu, L., Yue, X., and Venkatraman, S.: Statistical characteristics of the total ion density in the topside ionosphere during the period 1996-2004 using empirical orthogonal function (EOF) analysis, Ann. Geophys., 23, 3615-3631, doi:10.5194/angeo-23-3615-2005, 2005.

Zhao, B., Wan, W., Liu, L., Mao, T., Ren, Z., Wang, M., and Christensen, A. B.: Features of annual and semiannual variations derived from the global ionospheric maps of total electron content, Ann. Geophys., 25, 2513-2527, doi:10.5194/angeo-252513-2007, 2007. 